\title{
Should Google Search Be Regulated as a Public Utility?
}

March 17, 2012

\author{
Mark A. Jamison \\ University of Florida \\ mark.jamison@warrington.ufl.edu
}

\begin{abstract}
:
I examine the validity of the arguments for regulating Google search and find that they are insufficient and that regulation would likely be counterproductive. Google search does not fit the traditional frameworks for justifying regulatory control, namely, the public utility concept, common carrier concept, and essential facilities doctrine. For example, Google's search is not monopolistic in nature, does not preclude rivals from competing against Google, does not rely upon grant of a franchise as does a utility, and does not take control of rivals' content or service. Furthermore, the advocates for regulation fail to give adequate weight to the changes that constantly occur in the search business, the ways that rivals benefit from Google's investments, the negative impacts of forcing Google to reveal its search algorithms, and regulation's stifling effect on innovation.
\end{abstract}

JEL Codes: K21, K23, L12, L13, L42, L51

*The author is Director, Public Utility Research Center, and Senior Lecturer in Economics, Warrington College of Business Administration, University of Florida. I would like to thank Dr. Janice Hauge for her suggestions and Google for its financial support. I am solely responsible for the content. 


\section{Introduction}

The success of Google search, which reportedly provides about $65 \%$ of general ${ }^{1}$ Internet searches in the U.S. (Womack 2011), has resulted in a number of calls for regulation from industry observers and rivals, and has prompted investigations by antitrust regulators in the U.S. and in Europe. ${ }^{2}$ The advocates of government intervention evoke traditional arguments supporting economic regulation. Some hold that Google search is like a public utility because Google has a monopoly in their opinions and general search is important (Newman 2011; Simpson 2011). ${ }^{3}$ A second argument asserts that Google is a common carrier and should be regulated as such (Newman 2011). Others simply state that Google has market power in general search and, therefore, should be subjected to the essential facilities doctrine (Clemons and Madhani 2010-11; Edelman 2010, 2011b, 2011c). Regardless of the justification used, the advocates all reach the same conclusion, namely that governments should impose restrictions on Google designed to benefit its rivals.

Do these arguments for regulation stand up under careful scrutiny? In this paper, I examine the regulation proponents' claims and conclude that they are incorrect. I further conclude that regulation would be counterproductive. In a nutshell, regulation of Google search is inappropriate because Google search is not a monopoly ${ }^{4}$ and does not qualify as a public utility or as a common carrier. Furthermore, search technologies and markets are constantly changing, which would make regulation costly both in terms of the administrative costs and in terms of the delays in innovation that regulation would cause. Also, economic regulation of Google search could decrease investment by Google, which would likely harm customers and rivals. It could also result in at least partial public disclosure of Google's search

\footnotetext{
${ }^{1}$ There are several forms of search, including many specialized forms of search and general Web search. I adopt the term "general search" to denote the latter form of search, which is offered by Google, Yahoo!, Bing, and others.

${ }^{2}$ Rasmussen (2011) finds that the public in general did not share this sentiment at the time of the Rasmussen survey. Seventy-seven percent of adults believed there was no need for the government to regulate the way that search engines select their search results. Only $11 \%$ believed such regulation was necessary. The most frequent Internet users were the least likely to favor regulation.

${ }^{3}$ See also, "Is Google too powerful?" BBC News, February 21, 2003, http://news.bbc.co.uk/2/hi/2786761.stm, accessed December 28, 2011.

${ }^{4}$ As I explain later in this paper, the term monopoly in the context of public utilities means that the firm serves $100 \%$ of its market, that the firm's monopoly service has no close substitutes, and that the monopoly status endures over time. I also use and define the term natural monopoly, which refers to the economic efficiency of the monopoly arrangement. I distinguish between monopoly and monopolistic as follows. I use the term monopoly in the traditional economic sense and use the term monopolistic to refer to a firm that either serves $100 \%$ of its market, or that faces competition only from rivals that are seriously disadvantaged by lack of access to a factor of production, namely an essential facility, that the rivals need to be anything more than small, fledgling providers. This distinction is important because the literature on utilities and the literature on essential facilities both use the term monopoly, but sometimes use different definitions. I adopt the utilities definition of monopoly for this paper and use the term monopolistic when discussing the essential nature of a firm that possesses an essential facility.
} 
algorithms, which would allow other businesses to behave strategically to improve their search rankings without benefitting consumers. I arrive at these conclusions by examining whether the public utility concept, common carrier concept, or essential facilities doctrine appropriately applies to Google search. I also examine the validity of a new argument for regulation created by the advocates, namely that economic regulation should be adopted if it would benefit actual and potential rivals. I summarize my findings before proceeding with the paper.

Public utilities are considered to be natural monopolies, receive a public franchise or certificate of public convenience and necessity, and are considered to be affected with the public interest; that is to say, utilities have special legal obligations and their performance has an extraordinary impact on social and economic functioning. Regulation of utilities by independent regulatory agencies encourages investment since utilities have long-lived assets that are vulnerable to opportunistic political actions ${ }^{5}$ (Glaeser 1927; Jamison 2011; Phillips 1993). As public utilities, electricity, gas, and water companies meet all of these criteria, ${ }^{6}$ but Google search meets none of them. Google search is not a natural monopoly as evidenced by the commercially viable general search services that compete with Google. ${ }^{7}$ Even if there were no rivals, the monopoly status would be fleeting because Internet-based markets are constantly evolving so that today's innovative service is tomorrow's relic. ${ }^{8}$ While Google search is clearly popular, it is not essential to our social and economic functions in the way that electricity and water are. Our economies effectively shut down without these traditional utilities because utilities occupy unique positions and provide public services (Glaeser 1927), but our economies would not shut down without Google search. ${ }^{9}$ Nor does Google operate with a public franchise: Entrepreneurs built the company

\footnotetext{
${ }^{5}$ The possibility of political opportunism is not an element of the definition of public utility, but it is a reason for regulating utilities using an independent regulatory agency (Jamison 2011). Since utilities have long-lived assets that are not fungible once investments have been made, political actors have an incentive to expropriate the investments for political gain. This is ultimately destructive for the utilities and their customers, but the importance of short-term political gain often trumps long-term needs. Regulatory laws that define property rights and processes for cost recovery constrain political opportunism (Spiller 2005).

${ }^{6}$ An exception might be telecommunications. The sector was once considered a natural monopoly and was protected from competition. The sector's monopoly status has changed, but some jurisdictions continue to impose utility-style regulation apparently because of traditions, some elements of the sector are still monopolistic, and the firms are considered common carriers.

${ }^{7}$ I provide evidence of this actual competition in Section III.

${ }^{8}$ Today's Internet winners are often tomorrow's also-rans. For example, in 1998 Fortune ran an article with the title, "How Yahoo! Won the Search Wars" (Stross 1998). According to the article, "Yahoo! has won the search engine wars and is poised for much bigger things."

${ }^{9}$ As I explain in more detail in Section III, a situation in 2009 illustrated how consumers quickly use alternatives to Google search. For about an hour on the morning of January 31, 2009, Google search results contained a noticeable error. During that period of time a large number of customers switched their search activity to Yahoo! and probably to other search engines (Google 2009; Vascellaro 2009).
} 
without government sanction, and if the company does not keep up with changing technologies and markets, the company loses business to substitutes and the loss has little impact on consumers or the economy.

Likewise, Google search is not a common carrier. A common carrier, such as a railroad or a telecommunications carrier, offers its service to the public, and the service consists of moving someone's goods or content from one place to another. Common carriers have special obligations because customers give over control of their property to the carriers, customers are dependent on the carriers to faithfully perform their service, and there are long-held traditions that the carriers should provide service on a non-discriminatory basis. Common carrier obligations are effected through economic regulation due to a belief that enforcement through contract law would be inefficient (Cherry 2003b, 2007-8). Google search is not a common carrier service since Google is not transporting someone else's information on that person's behalf, and Google's rivals do not give over control of their services to Google.

Nor is Google search an essential facility. The concept of essential facilities emerged in U.S. telecommunications because the incumbent provider, AT\&T, with its years of government-protected monopoly, had ownership control of assets that rivals needed to be able to compete with AT\&T and that rivals could not duplicate ${ }^{10}$ (Hausman and Sidak 1999). As I describe in more detail in Section III, there is a four-part test to determine whether a company should be subjected to this doctrine. The test ascertains if the firm is vertically integrated ${ }^{11}$ and monopolistic with control of the essential facility while denying access to the rival, and further establishes if the rival can duplicate the facility and if it is feasible for the firm to provide access to the rival. The firm must meet all four parts of the test. One disconnect between the essential facilities doctrine and the search situation is the direction of supply: An essential facility is provided by a vertically integrated, monopolistic firm to a downstream rival. This does not fit the search case because search is provided by Google (or a rival) to consumers. Indeed, downstream rivals are included in Google's search results without charge and without significant effort on the rivals' parts. ${ }^{12}$ Even if that were not true, Google search does not qualify as an essential facility because Google

\footnotetext{
${ }^{10}$ Other instances where courts have evoked the essential facilities doctrine include a case where a professional football team was denied access to the only suitable football stadium in the city (Hecht v. Pro-Football, Inc., 570 F.2d 982 (D.C. Cir. 1977), cert. denied, 436 U.S. 956 (1978)) and a case of denial of access to a monopoly electricity utility's distribution grid (Otter Tail Power Co. v. United States, 331 F. Supp. 54, 61 (D. Minn. 1971), modified, 410 U.S. 366 (1973) (citing the "bottleneck" theory)). Lipsky and Sidak (1999) describe other cases involving the doctrine.

${ }^{11}$ Vertical integration means the firm is engaged in more than one stage of production in sequence, for example, a farmer who produces corn and converts some portion of the crop to ethanol. If the farmer also sells corn to other ethanol manufacturers, the farmer would be considered to be selling the input, corn, to a downstream rival, the other ethanol manufacturer.

${ }^{12}$ As I explain in Section II, search engines typically include a catalogue of sites and, following a query by a search user, return a list of sites that appear to match the query. This is called the organic search. Google and other general search providers do not charge sites for being included in the organic search.
} 
search is not monopolistic, there are reasonable substitutes for making customers aware of rivals' services, and Google does not refuse to include rivals in its search.

Perhaps implicitly admitting that Google search does not fit the traditional frameworks for economic regulation, some authors, industry observers, and rivals have sought to invent a new framework. Edelman (2011b) invokes a vague public interest criteria in arguing that "search and search advertising are the foundation of online commerce," which he uses in support of his advocacy for the regulation of Google search. Also, holding that Google search is a natural monopoly, Patterson (2011) argues that governments should require Google to publically disclose changes in its search algorithms and to apply its algorithms consistently across all Web sites.

Even though the proposed regulation of Google appears to be motivated by a desire to benefit Google's rivals, ${ }^{13}$ it is unclear that regulation would indeed benefit Google's rivals, let alone consumers. Google's interests in multiple Internet-based services provide the company with a profit incentive to improve its general search even more than would otherwise be the case. Quite simply, increased use of Google search increases the probabilities of customers accessing Google's other services, regardless of whether Google favors its own services in general search. The resulting higher profits in Google's other services provide a profit incentive for Google to increase the value customers find in Google search. Improved Google search creates potential spillover benefits for Google's rivals because improved Google search functionality leads customers to increase their use of the Internet and search for obtaining services, which leads to increased demand for rivals' information and products. Furthermore, government-imposed standards for presenting search results would likely stifle innovation. As happened in telecommunications, government oversight was imposed with the intention of protecting telephone companies' rivals; instead, it delayed technological progress and decreased innovation (Prieger 2002).

The remainder of this paper is organized as follows. The next section describes the history of Internet search and how search engines work. Section III describes the foundations for the traditional rationales for regulation and assesses whether search fits these categories. Section IV examines other rationales offered for regulating Google. Section $V$ is the conclusion.

\section{Search}

A search engine is a computer program that searches documents and other web content based on a user query and returns a list of relevant results to the search user. For example, entering "Internet search" into Microsoft's search engine Bing yielded "Web search engine - Wikipedia, the free

\footnotetext{
${ }^{13}$ Miller and Oliver (2012) explain that the current push for regulation of Google is largely rent seeking by rivals since customers are always free to choose another general search engine and consumers are generally happy with Google search. Consumers' preferences for Google search over other general searches are evidenced by the choices consumers make - about $65 \%$ of general searches are performed with Google search in the U.S. (Womack 2011) - and by the American Consumer Satisfaction Index (2012), which reports that consumers consistently rate Google higher than other general search engines in terms of consumer satisfaction.
} 
encyclopedia" as the first choice and "Freeality Internet Search Engines" as the second. ${ }^{14}$ There were over 2.4 billion documents listed. When a user enters a query, the search engine software accepts the query and checks for possible input errors, gathers and ranks a list of relevant pages from the engine's index or catalogue, checks to see if other databases (such as news search) are relevant to the query, gathers relevant advertisements, and returns the results to the user. The index or catalogue is built mechanically by Internet spiders, manually by humans, or both. Spiders search the Web - following links, requesting pages, reading pages for content, and indexing the information found into the catalogue. Search results from the catalogue are often called organic search (Sullivan 2002; Wall undated).

Although many of the underlying software technologies that make up a search engine predate the Internet, they came together for the Web in 1993, about two years after the introduction of the Web itself. According to Wall (undated), four search engines were launched in 1993; the best known of which was Excite. Early search engines, such as Yahoo! Directory launched in 1994, were often manually constructed directories that were costly and difficult to scale up. Meta search engines, which draw results from multiple search engines, emerged to leverage the diversity of individual engines.

The usefulness of search results to a user is determined largely by whether the content the user seeks or content containing the information the user seeks is ranked highly by the search engine and thus is listed highly in the search results. There are a variety of methods for determining the relevancy of content to a query, and search engines vary in the methods they use and in how they combine the methods. The location/frequency method looks for keywords in page titles and text, and generally assumes that if the keyword is in the title, then the page is more relevant than if the keyword appears only in the paragraphs of the document. Also, the more frequently a word appears on a page, the more relevant the page is considered to be to the query; however, a page may be considered to be spamming if a keyword appears to occur too often. Search engines can track how often a site is selected based on keywords and rank more highly those pages that receive more clickthroughs (Joachims 2002; Sullivan 2002). In 1998, Google was launched with a unique relevancy technology called PageRank, which measured a Web page's importance according to the number of links to it, and the number of links linking to those Web sites, similar in concept to how citations are used to measure the relative importance of academic publications (Google 2011a, 2011b). Users found the results of this process for ranking pages valuable relative to other approaches. Initially, Google provided its service to other search engines, such as Yahoo!, but these search engine providers chose to rely on their own engine algorithms and discontinued their use of Google's service. In response, Google launched its own search service and soon grew into the most popular site for general search.

Providers of general search are often multiproduct firms. Some providers, like Microsoft, launched general search engines after success in other sectors like PC software. Other general search providers have expanded beyond the traditional Web results into specialized results and more readily

\footnotetext{
${ }^{14}$ Query made January 2, 2012 by the author. A PDF of the first page of the search results is available from the author.
} 
accessible answers. These specialized search services (sometimes called vertical search) include video platforms such as YouTube, book search such as Yahoo!'s and Microsoft's Open Content Alliance, flight search, news search, and shopping search (Wall undated). For example, the query "Internet competition" in Bing yielded several tabs on its first page, including a "Videos" tab. An identical query into Google search also yielded several tabs on its first page, including a "Books" tab that listed books on Internet competition and a "Videos" tab. ${ }^{15}$

Search is free to users and search providers receive revenue primarily by selling advertising. For example, a query "pizza" in Google using Internet Explorer yielded three ads at the top of the first page. ${ }^{16}$ An early model for advertising was to charge commercial sites for being included in the search catalogue. The next innovation was pay per click, which is still in use and was pioneered by GoTo. In this model, an advertiser pays only if a user clicks on the advertiser's ad, which is often keyword targeted. The price per click is based on the keyword that the advertiser selects and can be set by the search provider or, as in the cases of Google's AdWords and Yahoo!'s Advertising Solutions, established through an auction process (Edelman, Ostrovsky, and Schwarz 2007; Wall undated). The pay per click model decreases risk for advertisers relative to paying simply for ad placement. It also facilitates targeted advertising because advertising platforms like those of Google and Microsoft factor the clickthrough rate into the click price, offering lower per-click prices to advertisers that are selected more often, and because search providers have an incentive to display more frequently ads that have higher clickthrough rates (Wall undated; Google 2011c). Another advertising model is content-targeted advertising, which places ads in Web sites based on the content of the sites. Owners of Web pages are compensated when viewers click through on an ad, and the advertiser pays an ad placement service, such as Google's AdSense (Google 2011d; Wall undated).

Today's three largest general search providers are Google, Yahoo!, and Microsoft. Other general search engines include the meta search engine Dogpile, which compiles searches of Google, Bing, and Yahoo!; AltaVista, which uses Yahoo!'s search technology; Go.Com, which is Disney's family friendly search engine; and Lycos. ${ }^{17}$ Newer general search engines include DuckDuckGo, which emphasizes privacy and new search algorithms, and Blekko, which emphasizes new search algorithms and less spam.

As is seemingly true of everything in the Internet, search is constantly evolving, which provides competitive pressures for general search providers (Manjoo 2011). Competition within general search is intensified by the constant development of improved technologies that add value for customers and lower costs. New substitutes are emerging for general search. Customers use Amazon for finding information about books, movies, and other products. Other retailing sites offer ways for customers to

\footnotetext{
${ }^{15}$ Queries made February 7, 2012 by the author. A PDF of the first page of each of the search results is available from the author.

${ }^{16}$ Query made January 2, 2012 by the author. A PDF of the first page of the search results is available from the author. Interestingly, the top two results from the organic search were the same as the top two ad results.

${ }^{17}$ The Search Engine List, http://www.thesearchenginelist.com, accessed January 7, 2012.
} 
share information and links to places of interest. Apps, such as OpenTable bypass search altogether. Social networks such as Facebook, LinkedIn, and Twitter offer features for finding information, getting recommendations, and reviewing products and services. Some industry observers believe that Apple's new Siri service is the next generation for search. Numerous mobile apps, such as barcode readers, travel apps, product and place reviews, and markets help customers find specific information in the right context. More specialized search services, including eBay, Kayak, Orbitz, Epicurious, Monster, Wikipedia, Yelp, UrbanSpoon, MapQuest, and Wolfram Alpha, are also targeting specific customer needs.

III. Foundations for Economic Regulation

I now turn my attention to whether Google search qualifies for regulation as a public utility, a common carrier service, or an essential facility.

Public Utilities

While the economic regulation of business has a long history, the regulation of public utilities evolved largely over the last 150 years and mostly in the U.S. Industries are considered to be public utilities if they tend to be natural monopolies, receive a public franchise or a certificate of public convenience and necessity, and are affected with the public interest (Glaeser 1927; Phillips 1993). I explain each of these criteria next.

Natural Monopoly. For the purposes of identifying a utility, the firm is considered to be a monopoly ${ }^{18}$ if it "cannot be operated with efficiency and economy unless it enjoys a monopoly of its market" (Bonbright, Danielsen and Kamerschen 1988). The utility is thought to serve $100 \%$ of its market ${ }^{19}$ (Sharkey 1982), but customers may have options at the margin, such as self-supply of electricity generation or streams and wells in the case of water. There can be no close substitutes for the monopoly's product or service (Harris and Simons 1989; Werden 1998) and there must be barriers to entry so that the monopoly's status persists over time ${ }^{20}$ (Hovenkamp and Areeda 2011).

\footnotetext{
${ }^{18}$ Some authors such as Simpson (2011) use the term "monopoly" or "monopolist" to characterize Google even though the firm serves less than $100 \%$ of its market. Others such as Clemons and Madhani (2010-11) use the term "monopoly power," which presumably admits that Google serves less than $100 \%$ of its market, but retains the characterization. Such uses of the terms "monopoly" or "monopoly power" may be normal in some contexts, but in the context of public utilities, the norm has been for "monopoly" to mean a firm that serves $100 \%$ of its market demand, not merely a firm that has a large market share.

${ }^{19}$ A firm may be considered to be monopolizing a market if it serves less than $100 \%$ of its market, but is taking steps to become the only active seller in the market (Viscusi, Vernon, and Harrington 2000). As such, monopolization is a term denoting the process of moving towards becoming a monopoly.

${ }^{20}$ Market power, which is the ability to receive revenue in excess of economic costs without the threat of entry (Hovenkamp and Areeda 2011), may exist even if a firm is not a monopoly. The presence of market power is not an element of the definition of utility.
} 
The most common approach to determining whether a firm is a natural monopoly is to examine the market from a production technology perspective. ${ }^{21}$ In this view, a monopoly is a natural monopoly if its production costs are subadditive, meaning that a single firm is the least cost arrangement for serving the entire market demand (Sharkey 1982).

Empirically demonstrating natural monopoly is technically difficult (Jamison 2000), so many people resort to citing anecdotal evidence, such as appearances of economies of scale. This is the approach adopted by FairSearch (undated) in arguing that other search engines cannot compete with Google. But this simplistic approach is inadequate, not only because it is devoid of any real data or conclusive evidence, but also because it is based on a faulty theory that the presence of scale economies is a sufficient condition for natural monopoly. Economists demonstrated long ago that this theory is insufficient for multiproduct firms. ${ }^{22}$ Even if scale economies were sufficient for making a firm a natural monopoly, the notion of scale economies explicitly assumes static technologies and markets, neither of which is present for search technologies (Sharkey 1982).

Clemons (2011) adopts another back-of-the-envelope method for identifying whether a firm is a natural monopoly, or at least has monopoly power, which is to observe whether the firm has unusually high temporal profits. ${ }^{23}$ However, the appearance of high temporal profits is insufficient for such a finding since the profit measure omits relevant costs and, used by itself, ignores the possibility of the firm having unique qualities. The amount of temporal profit a firm receives is directly related to the value of its products and its technical efficiency. ${ }^{24}$ Stated simply, higher value and lower costs deliver financial rewards to the firm and economic efficiency to society as a whole (Lipsky and Sidak 1999). Innovations that create such value should be encouraged, not discouraged by threats of regulation. However, my point here is that important costs are missing from the calculation of temporal profits, namely the financial outlays, risks, and other opportunity costs incurred in creating the innovative products, including the numerous failures that occurred along the way. These costs are not included in the measures of current profits, but are very real to existing businesses, entrepreneurs, and investors.

\footnotetext{
${ }^{21}$ There is at least one other approach, namely to define a firm as a natural monopoly if a single firm represents the only market structure that can receive non-negative profits (Tirole 1988). This approach does not lend itself to empirical testing because it lacks specific properties of costs, demand, and other factors that lead to such an outcome. Falling into this view, however, would be the notion of destructive competition, which is the idea that an industry with high fixed costs and homogenous products will tend to experience price wars that drive firms out of business until only one is left (Hovenkamp 1989).

${ }^{22}$ As I demonstrate in Section II, many providers of general search, including the leading providers, are multiproduct firms.

${ }^{23}$ Following what appears to be the definition for profit used by Clemons (2011), I define temporal profit as earned revenue less production costs and other investment costs for a firm for a specific period of time.

${ }^{24}$ Technical efficiency is the measure of the firm's ability to minimize costs for a given output level at a specified quality.
} 
They must believe such costs can be recovered and future profits received in order to be willing to take risks and invest in innovations. ${ }^{25}$

Public Franchise and Affected with the Public Interest. The concepts of public franchise ${ }^{26}$ and "affected with the public interest" are interrelated for utilities. ${ }^{27}$ Governments give utilities special privileges, such as the power of eminent domain, and impose special obligations, such as affirmative obligations to serve a particular territory, to charge non-compensatory rates in certain circumstances, and to not withdraw service without government permission (Cherry 2003a). For example, the service territories of electric utilities in the U.S. are specified by state utility regulators, and the firms are granted certificates of convenience and necessity. In some jurisdictions, this arrangement takes the form of contracts between the service provider and the government (Bakovic, Tenenbaum, and Woolf 2003). In other jurisdictions, the arrangement is spelled out in licenses or in statutes. The privileges are viewed as necessary because the utility uses public resources, such as rights of way; the utility sometimes needs the privileges to secure needed private resources, such as access to private property; the utility provides services that are commonly understood to be essential to the operation of a modern society; and the utility is a government-sanctioned monopoly, whose boundaries must be defined, who should not be allowed to restrict supply in order to raise prices, and whose obligations are used as an instrument of government to convey economic favors on particular groups, such as low-income households or certain industries.

\section{Applying the Public Utility Concept to Google Search}

Google search does not fit the definition of a public utility because it is not a monopoly and does not appear to be a natural monopoly, it has not received a public franchise, and it is not affected with the public interest. I focus here on the monopoly issue because Google has not received a public franchise for Internet search, and I address the public interest issue in Section IV.

Google Search not a Natural Monopoly. That Google search is not a monopoly is evidenced by the number of search rivals, both general search and specialized search, some of which I list in Section

\footnotetext{
${ }^{25}$ Temporal profits serve a valuable function in the marketplace in that they attract competition. For example, industry observers claimed in 1998 that Yahoo! owned general Internet search (Stross 1998). But Google's founders discovered uniquely valuable search algorithms, and the company became the industry leader. Today general search providers such as DuckDuckGo and Blekko assert that they have developed algorithms that are superior to those of Google. Whether these companies are correct and should succeed in the marketplace should be determined by customers, not by regulations that seek to hinder Google.

${ }^{26}$ Public franchises are also granted to cable television providers even though they are not classified as public utilities.

${ }^{27}$ The U.S. Supreme Court defined utilities as its own category of firms affected with the public interest. Chas. Wolff Packing Co. v. Court of Ind. Relations, 262 U.S. 522 (1923).
} 
II. ${ }^{28}$ Indeed, emerging general search providers such as DuckDuckGo are receiving funding by venture capitalists, implying that at least some investment experts believe that Google's market position is vulnerable. Despite this evidence, it is argued that Google search is a natural monopoly (Siegler 2012), implying that the existence of rivals is transitory. I offer arguments below as to why I believe this is not the case. $^{29}$

A proper economic test for natural monopoly for Google search would consider the multilateral rivalry that Google faces and the economics of joint production of all of the services that could be produced with search. Multilateral rivalry exists when a firm faces competition from rivals that are diverse in their mixes of markets (Jamison 2000). For example, in the 1970s, AT\&T faced competition primarily from firms like $\mathrm{MCl}$ that were more specialized than AT\&T in that they offered only long distance calling, dedicated data lines, or both, but not all of the services that AT\&T offered and no services that AT\&T did not offer. But over time, new patterns of rivalry emerged so that now AT\&T faces competition from software, networks, and devices provided by firms such as Google, Microsoft, Apple, and Vodafone that are in different sets of markets than is AT\&T, and few if any of the major firms are in the same set of markets as any of their rivals. This is multilateral rivalry.

To properly test for natural monopoly in a multilateral framework, an analyst must take into consideration the cost features of all of the rivals that impact the market in question, including firms that are outside of the market but that impact rivals in the market and substitutable products ${ }^{30}$ (Jamison 2000), plus the costs that customers incur to purchase the product(s). ${ }^{31}$ The empirical test for natural monopoly should examine the economics of production for all firms providing search and their rivals in

\footnotetext{
${ }^{28}$ According to Womack (2011), in November 2011 Google search's market share in general search slipped from $65.6 \%$ to $65.4 \%$, Yahoo!'s market share slipped from $15.2 \%$ to $15.1 \%$, and Microsoft's market share grew from $14.8 \%$ to $15 \%$.

${ }^{29}$ The burden of proof on whether Google is or is not a natural monopoly, or even whether it has market power, should be on those who hold that Google search should be regulated. If advocates of regulation were allowed to offer only unsubstantiated assertions (such as those by Clemons (2011) and FairSearch (undated)), and these assertions were considered substantive, the burden of proof would fall on the firm threatened with regulation. Such a process would allow rivals to use unsubstantiated claims to drive up a successful firm's costs. This would be wasteful and encourage rent seeking through the legal and political processes.

${ }^{30}$ In the case of search, substitutes for Google search include other general search services, specialized search, and some social networks.

${ }^{31}$ Some supporters of regulation argue that Google search is a monopoly because its size creates economies for advertisers that Google's rivals cannot match (FairSearch (undated); Hatch 2011). This view is based on assumptions of economies of scale for Google and economies of purchasing scale for advertisers. Economies of production scale and purchasing scale together, I call economies of market scale, implying that a single firm is the least-cost arrangement when both producer and purchaser costs are considered, assuming there are no joint economies with other products. The presence of economies of market scale are insufficient and not even necessary to cause natural monopoly in multiproduct firms, such as providers of search, even if technology is static, which it is not in the Internet.
} 
other markets, determine the cost-minimizing production arrangement(s) for all of their products, and identify whether a monopoly firm in general search is an element of that cost minimizing market structure (Jamison 2000). This is clearly a demanding task, and I know of no such study conducted for Internet search. The complexity of such an analysis points out the frailty of asserting natural monopoly based on casual claims of scale economies and switching costs. ${ }^{32}$

There are instances where simpler criteria are adequate for an economic test of natural monopoly. These include the cases of electricity distribution lines and water lines, where geography almost always makes duplicate lines uneconomical, and other means of obtaining service (e.g., selfgeneration of electricity and the hauling of water in containers) are almost always economically inferior. These situations are exceptions rather than the rule, and I am aware of no issues in Internet search that make new systems or alternative means of service clearly uneconomical.

Even if a proper cost test for natural monopoly were performed for general search, it would still be insufficient for demonstrating natural monopoly due to the dynamic changes occurring in the industry. One such change is in the costs of inputs. Computer technologies and telecommunications technologies are moving constantly, as is the rivalry in these sectors, which means that the costs of the inputs used to provide search are also constantly changing. Sharkey (1982) points out that, even if a firm is a natural monopoly with one set of input prices, it may not be with other sets of prices.

Moreover, the definition of search and the technologies of search are moving targets. For example, Apple is not considered a direct rival in general search, but its Siri product could be the next generation of search (Kaplan 2011). In some countries, search is conducted largely through nonspecialized software, such as Facebook. Indeed, the Bing search results for the "Internet search" query mentioned previously provided links to sites "liked" by Facebook friends. Services such as Yelp and UrbanSpoon for restaurants, and MapQuest for locations, are constantly changing and redefining the meaning of search.

\section{Common Carriers}

A common carrier is a firm that offers transport service to the public. For example, railroads and trucking companies are common carriers because they transport other people's goods. Common carriers have special obligations since customers give over control of their goods to a carrier and are dependent on the carrier to faithfully perform its service without harming the customers' property. For example, a telecommunications company carries others' electronic messages sometimes across the globe, and

\footnotetext{
${ }^{32}$ Ignoring customers' costs, it is possible to disprove the existence of natural monopoly with a production cost test developed by Baumol (1977) that is simpler than the multilateral study described above. This approach was applied by Serafica (1998) in the case of Philippines telecommunications, Armstrong and Leppel (1994) for combinations of electric and gas utilities, and Hogendorn (1998) for broadband. I know of no such studies conducted on Internet search. However, the Baumol test is insufficient for demonstrating the existence of a natural monopoly because it considers only the possibility of dividing production across smaller, more specialized firms (Jamison 2000).
} 
customers depend upon the companies to ensure that the messages do not change while in transit. Common carriers do not have to be monopolies (Cherry 2008). Although some common carriers, such as telecommunications, have also been traditionally classified as public utilities, this is not the general case as railroads, buses, and trucks are common carriers, but are not utilities.

The regulation of common carriers is based on the English common law concept of "public callings" and, in general, requires carriers to charge reasonable prices, serve without discrimination, and provide service skillfully and honestly. The concept of public callings came about to address perceived situations of economic coercion, exploitation, and misuse of bargaining power that resulted from shortages of tradesmen many centuries ago. The resulting regulation subjected certain businesses to the just price doctrine, which required that prices reflect the service's value for the community in general, that is to say, prices based on unique circumstances of specific buyers or sellers were not allowed (Baldwin 1959; Cherry 2007-8). These principles became embedded in U.S. law regarding common carriers because of market power abuses of railroads in the $1800 \mathrm{~s}$ and because the railroads were granted special privileges by the government (Cherry 2007-8).

\section{Applying the Common Carrier Concept to Google Search}

Google search does not fit the definition of common carrier since Google is not transporting someone else's property on that person's behalf, and Google's rivals do not give over control of their services to Google. As I describe in Section II, general search provides users with addresses of documents, ads, and specialized results such as video that are scored as highly relevant to the search query. Network providers, such as AT\&T and Verizon, are classified as common carriers as they provide transmission services to retail customers, Internet content providers, and search providers, making search engine users and the search engine providers' customers of the common carriers. Also, if Google search were to be considered as a common carrier service, then so would all search - including specialized search - because the categorization would apply to all firms performing the service regardless of individual market position.

Furthermore, Google search is not a public calling. While the public callings concept has evolved over time, its roots are in the context of situations where unusual circumstances leading to supply limitations gave certain tradesmen extraordinary power over customers and the ability to engage in what was considered extreme discrimination. While Google may have a large market share in general search in the U.S. by virtue of the majority of customers preferring Google's service to those of Google's rivals, I am unaware of any evidence that Google is restricting the supply of search results or searchbased ads any more than what is demanded by the physical or cognitive limitations of page space and the number of search queries that users submit.

\section{Essential Facilities Doctrine}

The essential facilities doctrine developed in a legal case between $\mathrm{MCl}$ and AT\&T in the U.S., ${ }^{33}$ but its foundations are in cases involving railroads, electricity distribution, airlines, and the like (Lipsky

\footnotetext{
${ }^{33} \mathrm{MCl}$ Communications Corp. v. American Telephone \& Telegraph Co. 708 F.2d 1081 (7th Cir. 1983).
} 
and Sidak 1999). The $\mathrm{MCl}$ case resulted from MCl's attempt to compete with AT\&T in long distance calls before AT\&T divested its ownership of local telephone lines. $\mathrm{MCl}$ could provide long haul transmission as a specialized common carrier, but needed local telephone lines to compete against AT\&T generally. AT\&T resisted providing access to its local lines and in the resulting case the court affirmed that AT\&T had to allow $\mathrm{MCl}$ access.

The doctrine is basically a refusal to deal issue (Cherry 2007-8) and holds that a monopolistic firm's refusal to grant rivals access to a facility that the rivals need to compete against the monopolistic firm can give rise to a legal antitrust liability. There is a four-part test to determine whether the doctrine applies:

1. Is the vertically integrated operator a monopolistic firm in control of the essential facility?

2. Is the rival unable practically or reasonably to duplicate the essential facility?

3. Does the vertically integrated operator deny use of the facility to the rival?

4. Is it feasible for the vertically integrated operator to provide access to the rival?

The existence of monopolistic control of a physical asset is fundamental to the doctrine (Lipsky and Sidak 1999). As Hausman and Sidak (1999) explain,

Inherent in the concept of an "essential facility" is the premise that the owner of that facility possesses monopoly power. The first two elements of the doctrine incorporate that recognition in a variety of ways. First, some degree of uniqueness and market control is inherent in the term "essential." Second, the inquiry regarding the impracticability of duplication ensures that the doctrine will apply only to facilities for which no feasible alternative exists or that cannot be reasonably reproduced. Finally, the term "facility" itself connotes an integrated physical structure or large capital asset with the degree of cost advantage or unique character that usually confers monopoly power and market control by virtue of its superiority.

Lipsky and Sidak (1999) explain that the degree of monopolistic control must be significant, although not necessarily absolute:

There will, of course, be instances in which the facility in question will be somewhat better than the alternatives, but not so much better as to preclude totally the continued survival of excluded parties. The present case law recognizes this distinction, and permits application of the doctrine where the competitive disadvantage is severe, rather than fatal.

There are several restrictions on the application of the essential facilities doctrine. A recent Supreme Court case - Verizon Communications, Inc. v. Law Offices of Curtis V. Trinko ${ }^{34}$ - while declining to explicitly endorse or reject the essential facilities doctrine, found that whether regulatory oversight

${ }^{34} 124$ S. Ct. 872 (2004). 
by an agency could force access is a significant question (Blair and Piette 2005). Lipsky and Sidak (1999) identify other restrictions:

- The monopolistic firm must control the relevant market. For example, in Drinkwine v. Federated Publications, Inc., ${ }^{35}$ a publisher of a weekly advertising tabloid sought distribution from a local newspaper, a request that the newspaper declined. The court found that while the newspaper was indeed a monopoly in its community, the relevant market was distribution and other methods were available, such as direct mail.

- Control of an essential facility does not convey market power if the market for the end product is competitive.

- It is problematic to apply the doctrine to intellectual property for the following reasons: (1) The significant probability of disclosure of the intellectual property, which would destroy the property's value; and (2) Mandatory sharing and compulsory dealings are inconsistent with the exclusivity that is necessary for incentives to create intellectual property.

Applying the Essential Facilities Doctrine to Google Search

Google search does not fit the definition of an essential facility because inclusion in Google search is not an input sold to rivals or other enterprises, Google does not exclude rivals from being included in search results, and Google search is not monopolistic. Furthermore, even if Google search is or contains an essential facility, remedies could decrease customer value or force Google to divulge intellectual property.

Inclusion in Google Search is not Sold and Google does not Exclude Rivals. In its early days, Yahoo! charged commercial Web sites for being included in its database (Wall undated). However, to my knowledge, this has not been a practice of general search engines since. Google and other general search providers finance their search operations by selling advertising, even to rivals. This business model gives Google an economic incentive to provide valuable search results to consumers because advertising revenue is positively correlated with the number of search queries. This incentive applies even in instances where the search results would rank rivals' sites as more relevant to the search parameters than a Google site.

Furthermore, Google does not exclude rivals from its search results. Google's critics appear to concede this point, although Edelman (2011a) asserts that Google restricts the supply of advertising for hotels by offering its own hotel booking service, Google Hotel Finder. However, he offers no evidence that the Google's introduction of its booking service resulted in a decrease in the supply of hotel advertising and does not explain how Google's provisioning of Google Hotel Finder might restrict supply. He simply asserts, "...Google raises price above marginal cost, restricts supply, and takes its pound of flesh from advertisers who have little alternative." Indeed, Edelman (2011b) contradicts his claim (Edelman 2011a) that Google restricts the supply of ads by asserting that Google has generally increased

${ }^{35} 780$ F.2d 735 (9th Cir. 1985), cert. denied, 475 U.S. 1087 (1986). 
its number of ads displayed: "And Google now shows as many fourteen (sic) ads on a page; users with mid-sized screens often must scroll to see the second algorithmic result."

Google Search is not Monopolistic. I demonstrate above that Google search is not a monopoly, so I focus here on whether Google search is monopolistic in the sense required for the essential facilities doctrine, which would mean that Google's vertical rivals would suffer a severe competitive disadvantage if Google were to deny them access to Google search. Examining whether this is true is necessarily a hypothetical exercise because I know of no evidence that Google denies rivals access to Google search.

Google would not impose a severe competitive disadvantage on its vertical rivals by denying them access to Google search because the rivals have economical alternatives for attracting users to their Web sites. This is evidenced by the willingness of vertical rivals to compete with Google, the lack of control that general search engines have over customers' Web site choices, and customers' willingness to choose general search engines other than Google.

Vertical Rivals' Willingness to Compete with Google. Edelman (2011a) asserts that Internet entrepreneurs and investors are unwilling to launch new, vertical services that would compete with Google Maps and YouTube, for example, because Google's search algorithms foreclose competition. Actual experience demonstrates the falseness of this assertion. Regarding whether firms would be willing to compete with YouTube, rivals blip.tv, Flikr, Dailymotion, and Vimeo have existed alongside YouTube since its inception. Rival Veoh was launched in 2007, months after Google acquired YouTube and, at the time of this writing, has financial backing from the likes of Goldman Sachs. A Twitter-linked video service, Yfrog, was launched in 2009, at least two years after Google's purchase of YouTube. Competitors to Google Maps include Bing maps (Microsoft), OVI maps (Nokia), and an open source alternative, Open Street Map. Also, as Kayak described in its Form S-1 filed with the U.S. Securities and Exchange Commission, during the first nine months of 2010, $72 \%$ of Kayak's volume was generated by people going directly to its Web site and only $8 \%$ came from general search engines. ${ }^{36}$ Furthermore, as I explain above, DuckDuckGo is finding venture capital, contrary to Edelman's claim. To its credit, Blekko is resisting the temptation to try to hamstring rivals with regulation, saying instead that it would prefer to compete with Google and others without government intervention. ${ }^{37}$

Alternatives to Google Search. The presence and prominence of economical alternatives to Google search demonstrate that, while it is to any firm's advantage to be present in Google search results, exclusion by Google would not be fatal, or even severely harmful.

Although Google provides $60 \%$ to $70 \%$ of the general searches in the U.S. (Womack 2011), users still do not find themselves tied to Google. According to research by Performics (2010),

\footnotetext{
${ }^{36}$ See Kayak Software Corporation. Form S-1 Registration Statement with the U.S. Securities and Exchange Commission, filed November 17, 2010. http://www.sec.gov/Archives/edgar/data/1312928/000119312510262521/ds1.htm, accessed February 9, 2012.

37 See “Blekko's Not Afraid of Google, Why is Washington?" http://www.skrenta.com/2011/09/blekkos_not_afraid_of_google_w.html, accessed February 9, 2012.
} 
1. $66 \%$ of users who prefer Google use a different search engine either frequently or occasionally;

2. $89 \%$ of users try a different search engine if they cannot find what they are searching for with their preferred engine;

3. new users are most likely to use Yahoo! as their search engine.

An incident in 2009 illustrates how readily and easily consumers switch to alternative sources of general search if Google fails to perform according to their expectations. For about an hour on the morning of January 31, 2009, a human error at Google caused each and every Google search result to contain the message "This site may harm your computer" (Google 2009). Even though the problem was short-lived, customers quickly moved to other search engines. During the one-hour time period that Google had the error, the number of Yahoo! searches doubled compared to the normal load (Vascellaro 2009). Once Google fixed the problem, customers quickly switched back to Google, indicating the quickness with which general search users recognize problems and adapt their behavior so that they are using the general search engine that provides them with the greatest value.

One use of general search is navigational queries. This decreases the influence that a search engine can have on directing results. Searching for known sites means that people use search to link to a site instead of typing in the URL. For example, Experian Hitwise identified the 10 most-searched terms for 2011 as "facebook," "youtube," "facebook login," "craigslist," "facebook.com," "yahoo," "ebay," "www.facebook.com," "mapquest," and "yahoo.com." "38 Users were searching for "facebook," for example in lieu of typing "www.facebook.com" in the browser address bar. Thus for the most popular searches, typing the URL into the browser address bar is a suitable substitute for search.

Search User Independence. Although search is important, it does not determine customer behavior: Customers exercise discretion in making their choices. Even as early as 2005, before the recent rise of Facebook and smart phone apps as alternatives to general search, customers demonstrated their independence of search engine results. Qiu, Liu, and Cho (2005) find that search engines influenced only $13.6 \%$ of users' Web traffic at the time of the study. According to early Pew Research results about that time (Pew 2005), only 44\% of searchers regularly used just one search engine and two-thirds said they could stop using search engines without disrupting their lives very much.

According to Pew (2011), about 92\% of adult Internet users use search engines and studies often find that users generally select the first, second, or third items listed in search results. But such findings do not mean that a search engine easily skews outcomes. Skewed results diminish the value to users, who are quite willing to change search engines. Indeed, the preponderance of first through third items being selected may mean that the search engines are working well. Also, according to the Performics (2010) study, (1) Users pay attention to the descriptions of the search results listed: $88 \%$ say they are more likely to select a search item if the item contains the exact words or phrases included in the query;

\footnotetext{
${ }^{38}$ Paris, Joseph, "People Still Use Search to Find the Most Popular Websites," The Verge, December 25, 2011 http://www.theverge.com/2011/12/25/2657912/people-search-popular-websites, accessed January 5, 2012.
} 
(2) $89 \%$ of users modify their query if a search does not provide the desired item(s); and (3) $79 \%$ of users look beyond the first page of search results if it does not contain what they are looking for.

Advertiser Independence. Likewise, academic studies cast doubt on whether search advertising is an essential facility. Studies by Ratliff and Rubinfeld (2010) and Goldfarb and Tucker (2011a, 2011b) find that offline advertising constrains prices for online advertising, implying that advertisers have effective alternatives to online advertising in general. They further conclude that search-based advertising and non-search-based advertising compete with each other, meaning that search engine providers have no market power relative to other online advertising providers. These study results conflict with the statement by the Federal Trade Commission (2007) in approving Google's acquisition of DoubleClick, so Ratliff and Rubinfeld (2010) explain where the FTC erred in its analysis. Consistent with the findings of Ratliff and Rubinfeld and of Goldfarb and Tucker, the Performics (2010) study finds that organic search results could serve to limit the amounts that advertisers are willing to bid to appear in search advertising because users favor organic search results over ads: $79 \%$ always or frequently select items in the organic search, while $80 \%$ only occasionally, rarely, or never select ads. There is also evidence that other forms of online advertising serve as substitutes for search advertising: eConsultancy (2011) finds that the greatest growth in online advertising is with Facebook, not with search engines, that $35 \%$ of online advertisers have recently moved budget from search advertising to advertising on Facebook, and that $23 \%$ of online advertisers have moved budget from search to display ads.

Ease of Duplication. Another problem with applying the essential facilities doctrine to Google search and search advertising is that the doctrine is designed for resources that are difficult to duplicate, such as physical facilities, but Google's products are based in software and intellectual property (Lipsky and Sidak 1999). As is demonstrated by Google's success overtaking once dominant Yahoo! in general search, and by the constant launching of new general search engines and new substitutes for search, the openness of the Internet makes it relatively easy for new services and companies to innovate and overtake the old guard. This ease of duplication and replacement contradicts a basic premise of the essential facilities doctrine, namely that the resource cannot be economically obtained by any other means. That the resource is intellectual property (Patterson 2011) only expands the mismatch between the doctrine and search because of the industry's dynamic nature and because applying the doctrine would necessarily divulge Google's trade secrets.

As my description of the history of search in Section II demonstrates, search technologies are always changing. Indeed, according to Google, its research and development efforts in 2010 included the following: ${ }^{39}$

- 13,311 tests of potential algorithm changes to determine how they impacted the precision of search results

- 8,157 experiments where users compared pages of search results side-by-side to assess user value

${ }^{39}$ Google Web site, http://www.google.com/competition/howgooglesearchworks.html, accessed January 6, 2012. 
- 2,800 click evaluations to see how a small sample (typically less than $1 \%$ of Google's users) responded to a change

These efforts resulted in more than 516 improvements in 2010, more than one per day. Yahoo! is investing in the human experience in search, having hired a team of well-known scientists from leading universities to work with Yahoo!'s team of cognitive psychologists, sociologists, economists, and ethnographers. ${ }^{40}$ Google's and Yahoo!'s efforts in innovation imply many things. One is that user value is constantly increasing in the current environment. This challenges the notion that search engine providers are exerting market power: The providers may be influential, but the market is clearly a moving target, making it difficult to exploit market power in any traditional sense.

Negative Impacts of Regulation. These investments in innovation also indicate the value of invention to the providers. The companies are investing significant amounts of money to advance their technologies, presumably in anticipation of profiting from the investments. Regulation would likely decrease the rate of innovation in several ways, which would diminish customer value and the competitiveness of the sector:

1. Regulation might result in innovative search engine providers divulging their intellectual property directly to rivals. Any potential transfer of such information to a rival decreases the innovator's expected profit, which in turn diminishes the incentive to innovate.

2. Regulation would necessitate search engine providers divulging their intellectual property at least to government officials, with the likely outcome of information leaking to rivals.

3. Even if government officials were able to protect intellectual property, the probability of leaks would exist, which would diminish the expected profits from innovation, which in turn would decrease the incentive to invest.

4. Information would likely become available to Web site owners, who could use it to manipulate search engine results in their favor. This would diminish the value of search results to users. In order to protect the value of search results, search engine providers would need to make additional investments to thwart the manipulation, which would increase the cost of innovation.

5. Search engine providers would need to submit technology changes to regulators for their approval. Review times would necessarily delay invention and the additional costs would discourage change, similar to the case of regulatory rules for information services by telecommunications firms (Prieger 2002). This would be unworkable in the general search industry where innovations are introduced at a rate of more than one per day. ${ }^{41}$

6. Regulation would also likely lock at least the dominant search engines to outdated models of Internet search and freeze their evolution, even while rivals move forward. This would diminish the influence of Google, but would also make Google less valuable to consumers (Crane 2011).

\footnotetext{
${ }^{40}$ Yahoo! Labs, http://labs.yahoo.com/news/166, accessed January 6, 2012.

${ }^{41}$ Google Web site http://www.google.com/competition/howgooglesearchworks.html, accessed January 6, 2012.
} 
7. Regulation would lock in industry and product boundaries that will be outdated even as the rules are being put in place, further delaying innovation (Jamison and Sichter 2010).

\section{Other Rationales for Regulating Google}

\section{Public Interest Criteria}

While not explicitly using the phrase "affected with the public interest," Edelman (2011b) appears to invoke the concept in arguing that Google "search and search advertising are the foundation of online commerce" in support of his notion that Google search should be regulated.

The precise meaning of a firm being affected with the public interest has evolved over time. ${ }^{42}$ In an 1876 case involving Illinois grain elevators, the U.S. Supreme Court identified such firms as including those that exercise "a sort of public office" and stand at the "gateway of commerce." As the Court explained, the Illinois grain elevators were uniquely situated between the river harbor and the railroad tracks. It was virtually impossible to move either the harbor or the rails, so the elevators were "virtual monopolies" for storing and transferring grain coming from "seven or eight great States of the West." ${ }^{\prime 3}$

In 1923, the Court refined the definition, dividing firms affected with the public interest into three categories:

(1) Those which are carried on under the authority of a public grant of privileges which either expressly or impliedly imposes the affirmative duty of rendering a public service demanded by any member of the public. Such are the railroads, other common carriers and public utilities. (2) Certain occupations, regarded as exceptional, the public interest attaching to which, recognized from earliest times, has survived the period of arbitrary laws by Parliament or colonial legislatures for regulating all trades and callings. Such are those of the keepers of inns, cabs, and gristmills. (3) Businesses which, though not public at their inception, may be fairly said to have risen to be such and have become subject in consequence to some government regulation. They have come to hold such a peculiar relation to the public that this is superimposed upon them. In the language of the cases, the owner, by devoting his business to the public use, in effect grants the public an interest in that use and subjects himself to public regulation to the extent of that interest although the property continues to belong to its private owner and to be entitled to protection accordingly. ${ }^{44}$ (cites omitted)

Glaeser (1927) explains that the third category is meant for the firms at the gateway of commerce, such as the Illinois grain elevators. He further points out the importance of the word

\footnotetext{
${ }^{42}$ See Glaeser (1927) and Cherry (2003a) for descriptions of the history.

${ }^{43}$ Munn v. Illinois, 94 U.S. 113, 130-132 (1876).

${ }^{44}$ Chas. Wolff Packing Co. v. Court of Ind. Relations, 262 U.S. 522, 535 (1923). Citations omitted.
} 
"peculiar," noting that all businesses affect the public welfare, and the only sensible way to understand the third category is to consider that these firms have an unusually close relationship to the public.

Google search does not fit any of these categories of firms affected with the public interest. I have already explained that Google search is not a utility; nor is search a public calling. But Edelman (2011b) appears to argue that Google search is the foundation of online commerce and so sits at the gateway of commerce, an argument made more explicitly by Simpson (2011). If these arguments were correct, Google search would fit the third category -- businesses which, though not public at their inception, may be fairly said to have risen to be such and have become subject in consequence to some government regulation -- so I examine whether Google search is a gateway to commerce in the same sense as the Illinois grain elevators.

Google search does not possess such a privileged position. Certainly, Google is successful in making itself valuable, but the value comes from Google's research and development into customers' search preferences, not, as with the grain elevators, from an accident of geography that cannot be changed. Indeed, many firms engaged in online commerce pay for certain URL names, implying that specific Web addresses have value, perhaps so that customers can easily remember the addresses and enter them directly. Furthermore, Google search has numerous rivals, as evidenced from their activity before the U.S. Congress and with antitrust agencies. Also, as I explain in Section III, search itself is not in a privileged position as online service providers use many methods to attract customers.

\section{Benefit to Competition Argument}

Supporters of regulation argue that regulating Google would benefit competition. ${ }^{45}$ Often the claims are offered without explanation, but taken together their essence appears to be as follows:

1. Benefitting competition is good.

2. Google's rivals represent competition.

3. Therefore, benefitting Google's rivals is good.

As I explain next, this is a faulty line of reasoning.

There would be general acceptance of the notion that increasing the number of firms in an oligopoly market is good, ceteris paribus, because it decreases prices, which increases consumer surplus. But the advocates of regulation never define what they mean by benefitting competition. It is unlikely that regulation advocates, such as Yelp and Microsoft, are supporting the idea that more firms should enter their markets, so their meaning remains unclear. I take the phrase to mean consumers benefitting from the competitive interactions among firms. Such interactions can benefit consumers through aligning prices more closely with costs, increasing the amount of service being made available, and stimulating more innovations that improve consumer value.

\footnotetext{
${ }^{45}$ Patterson (2011) and Hatch (2011) cite such arguments from Google's rivals and others. See also Edelman (2010) and FairSearch (undated).
} 
As my analyses in Section III shows, general search engines lack market power. My analyses in Sections II and III also demonstrate that search is a highly innovative industry and that some innovations are sufficiently significant to result in new industry leaders. I know of no evidence that this industry is lacking in innovation due to its current market structure. However, there are theoretical models that suggest a firm with a large market share can sometimes leverage that market share to advantage itself as a market grows in other markets. Cremer, Rey, and Tirole (2000) draw this conclusion in the case of the Internet backbone, and Carlton and Waldman (2002) do so in the case of software. The essence of these findings is that complementarities, such as network effects, help a firm with a larger market share in one market to gain market share in other markets. Missing from Cremer et al. (2000) and Carlton and Waldman (2002) is an analysis of how opportunities for future markets impact investments in today's markets. Jamison (2001) demonstrates that the opportunity to leverage complementarities across markets stimulates investment in existing markets. Applied to the case of general search, the opportunities for future generations of search-like products probably help motivate Microsoft's, Yahoo!'s, and Google's investments in search.

Implicit in the regulation advocates' arguments that regulation would benefit competition is a belief that benefitting rivals is the same as improving competition. Competition is improved if new interactions among firms decrease market power, make innovation more profitable, or both. This is different from helping rivals. The oversight advocated by the supporters of regulation appears intended primarily to help rivals by hindering Google. Hobbling one competitor from providing competitive pressure on others is unlikely to result in lower prices, more innovation, or any other outcomes that benefit customers. Indeed, the constraints on Google would more likely provide its rivals with an umbrella under which they could exist without much threat from what would otherwise be the most effective firm in the market.

An unstated premise in the advocates' argument for regulation is that Google's rivals, who believe that Google discriminates against them in search, would benefit from the same search value that Google creates today. As I explain above, a firm such as Google benefits from synergies across its search services, and that these synergies incent increased investment in search. If regulation were to decrease Google's incentives to invest in search, the diminished value of search could decrease the customer traffic that rivals receive from Google search. These results are sensitive to underlying assumptions about whether Google discriminates against rivals, the costs and benefits of such discrimination, and the costs and benefits of investment in Google search. However, the analysis is clear that a conclusion about the benefits rivals might receive from the regulation of Google depends on market and production characteristics that are currently unknown.

\section{Conclusion}

In this paper, I address the case for regulating Google search and find that the arguments are not compelling. The justifications are based on beliefs that Google search is a monopoly or at least a natural monopoly experiencing transitory competition, is affected with the public interest in the way 
that an electric utility is, performs a quasi-governmental function, provides transport services to rivals, or controls a facility that downstream rivals must obtain to compete with Google. None of these are true.

Also, fundamental to the regulation advocates' conclusions is the notion that Google discriminates against rivals. I have not inspected Google's algorithms to determine whether or how Google removes some documents from its search as I know some search rivals do, ${ }^{46}$ favors Googlerelated sites relative to non-related sites in Google search results, or engages in other activities that some of the advocates of regulation claim. Certainly, there are some incentives for Google to behave that way, but there are also offsetting incentives. For example, if discrimination diminishes the value of Google search and drives users to alternatives to Google search, the discrimination could be unprofitable. Furthermore, some discrimination can benefit customers if the discrimination leverages complementarities across products or markets. However, my interest here is not in whether the incentives exist or in whether Google acts on them. I leave that for other research. Rather my focus is on whether the arguments for regulation are substantial enough to justify economic oversight of Google even if such discrimination exists. I find that they are not.

\footnotetext{
${ }^{46}$ See for example Bing's banning of sites regarding Black Friday: "Banned Holiday Deal Sites Return to Bing," December 12, 2011, http://searchengineland.com/banned-holiday-deal-sites-return-to-bing-104479, accessed January 7, 2012.
} 
Bibliography

American Consumer Satisfaction Index. 2012. "Scores by Company: Google."

http://www.theacsi.org/index.php?option=com_content\&view=article\&id=149\&catid=\&ltemid=214\&c= Google+, accessed February 5, 2012.

Armstrong, Thomas O., and Karen Leppel. 1994. "Are Regulated and Potentially Unregulated Combination Gas and Electric Utilities Natural Monopolies?" Journal of Economics and Business, 46(3): 195-206.

Bakovic, Tonci, Bernard William Tenenbaum, and Fiona Woolf. 2003. Regulation by Contract: A New Way to Privatize Electricity Distribution? Washington, D.C.: The World Bank.

Baldwin, John W. 1959. "The Medieval Theories of the Just Price: Romanists, Canonists, and Theologians in the Twelfth and Thirteenth Centuries." Transactions of the American Philosophical Society, New Series, 49(4): 1-92.

Baumol, William J. 1977. "On the Proper Cost Tests for Natural Monopoly in a Multiproduct Industry." American Economic Review, 67(5): 809-822.

Blair, Roger, and Christine Piette. 2005. "The Interface of Antitrust and Regulation: Trinko." The Antitrust Bulletin, 50(4):665-85.

Bonbright, James C., Albert L. Danielsen, and David R. Makerschen. 1988. Principles of Public Utility Rates. Arlington, VA: Public Utilities Reports, Inc.

Carlton, Dennis W., and Michael Waldman. 2002. "The Strategic Use of Tying to Preserve and Create Market Power in Evolving Industries." The RAND Journal of Economics, 33(2): 194-220.

Cherry, Barbara A. 2003a. "The Political Realities of Telecommunications Policies in the U.S.: How the Legacy of Public Utility Regulation Constrains Adoption of New Regulatory Models." Michigan State DCL Law Review, 2003(3): 757-790.

Cherry, Barbara A. 2003b. "Utilizing 'Essentiality of Access' Analysis to Mitigate Risky, Costly and Untimely Government Interventions in Converging Telecommunications Technologies and Markets." CommLaw Conspectus, 11: 251-275.

Cherry, Barbara A. 2007-8. "Maintaining Critical Rules to Enable Sustainable Communications Infrastructures." Georgia State University Law Review, 24: 947-975.

Cherry, Barbara A. 2008. "Back to the Future: How Transportation Deregulatory Policies Foreshadow Evolution of Communications Policies." The Information Society, 24: 273-291.

Clemons, Eric K. 2011. "Time to Wake Up and Smell the Antitrust." http://www.huffingtonpost.com/eric-k-clemons/post_888_b_732887.html, accessed October 21, 2011. 
Clemons, Eric K., and Nehal Madhani. 2010-11. "Regulation of Digital Businesses with Natural Monopolies or Third Party Payment Business Models: Antitrust Lessons from the Analysis of Google." Journal of Management Information Systems, 27(3): 43-80.

Crane, Daniel A. 2011. "Search Neutrality as an Antitrust Principle." University of Michigan Law School working paper.

Cremer, Jacques, Patrick Rey, and Jean Tirole. 2000. "Connectivity in the Commercial Internet." Journal of Industrial Economics, 48(4): 433-472.

eConsultancy. 2011. “Online Advertisers Survey Report 2011.”

Edelman, Benjamin. 2010. "Hard-Coding Bias in Google 'Algorithmic' Search Results."

http://www.benedelman.org/hardcoding, accessed October 12, 2011.

Edelman, Benjamin. 2011a. "Finding and Preventing Biased Results."

http://www.acslaw.org/acsblog/finding-and-preventing-biased-results, accessed October 12, 2011.

Edelman, Benjamin. 2011b. "Google's Dominance - And What To Do About It."

http://www.acslaw.org/acsblog/google\%E2\%80\%99s-dominance-\%E2\%80\%93-and-what-to-do-about-it, accessed October 12, 2011.

Edelman, Benjamin. 2011c. "Remedies for Search Bias." http://www.benedelman.org/news/0222111.html, accessed October 12, 2011.

Edelman, Benjamin, Michael Ostrovsky, and Michael Schwarz. 2007. "Internet Advertising and the Generalized Second-Price Auction: Selling Billions of Dollars Worth of Keywords." American Economic Review, 97(1): 242-259.

FairSearch. (undated). "Can Search Discrimination by a Monopolist Violate U.S. Antitrust Laws?" http://www.fairsearch.org/wp-content/uploads/2011/07/Can-Search-Discrimination-by-a-MonopolistViolate-U.S.-Antitrust-Laws1.pdf, accessed October 12, 2011.

Federal Trade Commission. 2007. "Statement of Federal Trade Commission Concerning Google/DoubleClick." (FTC File No. 071-0170) 3 and 7 (December 20, 2007), http://www.ftc.gov/os/caselist/0710170/071220statement.pdf.

Glaeser, Martin G. 1927. Outlines of Public Utility Economics. New York, NY: The Macmillan Company. Goldfarb, Avi, and Catherine Tucker. 2011a. "Advertising Bans and the Substitutability of Online and Offline Advertising." Journal of Marketing Research, 48(2): 207-227.

Goldfarb, Avi, and Catherine Tucker. 2011b. "Search Engine Advertising: Substitution When Pricing Ads to Context." Management Science, 57: 458-470. 
Google. 2009. “'This Site May Harm Your Computer' on Every Search Result?!?!”

http://googleblog.blogspot.com/2009/01/this-site-may-harm-your-computer-on.html, accessed

February 17, 2012.

Google. 2011a. "Google History." http://www.google.com/about/corporate/company/history.html, accessed January 7, 2012.

Google. 2011b. "Technology Overview." http://www.google.com/about/corporate/company/tech.html, accessed January 7, 2012.

Google. 2011c. "Advertise Your Business on Google." http://www.google.com/ads/adwords2, accessed January 7, 2012.

Google. 2011d. "What's AdSense." https://www.google.com/adsense/www/en_US/tour/index.html, accessed January 7, 2012.

Harris, Barry C., and Joseph J. Simons. 1989. "Focusing Market Definition: How Much Substitution is Necessary?" Research in Law and Economics, 12: 207-226.

Hatch, David. 2011. “Google's Dominance.” CQ Researcher, 21(40): 955-968.

Hausman, Jerry A., and J. Gregory Sidak. 1999. "A Consumer-Welfare Approach to the Mandatory Unbundling of Telecommunications Networks." The Yale Law Journal, 109: 417-505.

Hogendorn, Christiaan. 1998. "Market Structure and Broadband Networks: The Feasibility of Competition." (unpublished)

Hovenkamp, Herbert. 1989. "The Antitrust Movement and the Rise of Industrial Organization." Texas Law Review, 68: 105-168.

Hovenkamp, Herbert, and Phillip E. Areeda. 2011. Fundamentals of Antitrust Law, Fourth Edition. New York, NY: Aspen Publishers.

Jamison, Mark A. 2000. Industry Structure and Pricing: The New Rivalry in Infrastructure. Boston, MA: Kluwer Academic Publishers.

Jamison, Mark A. 2001. Restructuring in Network Industries: Competition and Mergers in Telecommunications. Unpublished dissertation, University of Florida.

Jamison, Mark A. 2011. "Liberalization and Regulation of Telecoms, Electricity, and Gas in the United States." In International Handbook of Network Industries: The Liberalization of Infrastructure, eds. Matthias Finger and Rolf W. Künneke, 366-383. United Kingdom: Edward Elgar.

Jamison, Mark A., and James Sichter. 2010. "Business Separation in Telecommunications: Lessons from the U.S. Experience." Review of Network Economics, 9(1): Article 3. 
Joachims, Thorsten. 2002. "Optimizing Search Engines Using Clickthrough Data." Proceedings of the Eighth ACM SIGKDD International Conference on Knowledge Discovery and Data Mining, ACM New York.

Kaplan, Dan. 2011. "Siri, Quora, and the Future of Search." Techchrunch.com http://techcrunch.com/2011/10/16/siriquora-and-the-future-of-search, accessed January 8, 2012.

Lipsky, Abbott B., Jr., and J. Gregory Sidak. 1999. "Essential Facilities." Stanford Law Review, 51(5): 11871248.

Manjoo, Farhad. 2011. "The Great Tech Wars of 2012." Fast Company, http://www.fastcompany.com/magazine/160/tech-wars-2012-amazon-apple-google-facebook, accessed December 13, 2011.

Miller, James C. III, and Daniel Oliver. 2012. "About the FTC's Star Trek Law Enforcement." The Examiner. February 5, 2012.

Newman, Nathan. 2011. "Will ITA Takeover Conditions Move Google Towards Becoming Public Utility?" Huffington Post, http://www.huffingtonpost.com/nathan-newman/will-ita-takeoverconditi_b_846754.html, accessed December 28, 2011.

Patterson, Mark R. 2011. "Should Regulators Treat Google Like Standard \& Poor's?" Forbes, http://law.fordham.edu/23868.htm, accessed December 28, 2011.

Performics. 2010. "Search Engine Results Page (SERP) Insights Study."

Pew Research Center. 2005. "Search Engine Users."

Pew Research Center. 2011. "Search and Email Still Top the List of Most Popular Online Activities."

Phillips, Charles F. Jr. 1993. The Regulation of Public Utilities. Arlington, VA: Public Utilities Reports, Inc.

Prieger, James E. 2002. "Regulation, Innovation, and the Introduction of New Telecommunications Services." The Review of Economics and Statistics, 84(4), 704-715.

Qiu, Feng, Zhenyu Liu, and Junghoo Cho. 2005. "Analysis of User Web Traffic with a Focus on Search Activities." University of California at Los Angeles working paper.

Rasmussen Reports. 2011. "Most Say No to Government Regulation of Search Engines." http://www.rasmussenreports.com/public_content/lifestyle/general_lifestyle/january_2011/most_say_ no_to_government_regulation_of_search_engines, accessed February 19, 2012.

Ratliff, James D., and Daniel L. Rubinfeld. 2010. "Online Advertising: Defining Relevant Markets." Journal of Competition Law and Economics, 6(3): 653-686.

Serafica, Ramonette B. 1998. "Was PLDT a Natural Monopoly? An Economic Analysis of Prereform Philippine Telecoms." Telecommunications Policy, 22(4-5): 359-370. 
Sharkey, William W. 1982. The Theory of Natural Monopoly. New York, NY: Cambridge University Press.

Siegler, M.G. 2012. "Google and the Monopoly Paradox." Aol Tech

http://techcrunch.com/2012/01/12/more-more-more, accessed January 12, 2012.

Simpson, John M. 2011. "You Can Read 'CQ Researcher' In-depth Report on Google's Dominance."

Consumer Watchdog, http://www.consumerwatchdog.org/node/12509, accessed December 28, 2011.

Spiller, Pablo T. 2005. "Institutional Changes in Emerging Markets: Implications for the

Telecommunications Sector." In Handbook of Telecommunications Economics: Volume 2, eds. Sumit

Kumar Majumdar, Ingo Vogelsang, and Martin E. Cave, 621-655. Amsterdam: North-Holland.

Stross, Randall E. 1998. "How Yahoo! Won the Search Wars." Fortune, March 2, 1998.

http://money.cnn.com/magazines/fortune/fortune_archive/1998/03/02/238576/index.htm, accessed

February 6, 2012.

Sullivan, Danny. 2002. "How Search Engines Rank Web Pages."

http://www.uniroma2.it/didattica/prog_web/deposito/search_engine.pdf, accessed December 31, 2011.

Tirole, Jean. 1988. The Theory of Industrial Organization. Cambridge, MA: The MIT Press.

Vascellaro, Jessica E. 2009. "Fresh Evidence That Search Is Still Competitive? Not So Fast." The Wall Street Journal, March 17, 2009, http://blogs.wsj.com/digits/2009/03/17/fresh-evidence-that-search-isstill-competitive-not-so-fast, accessed February 17, 2012.

Viscusi, Kip W., John M. Vernon, and Joseph E. Harrington, Jr. 2000. Economics of Regulation and Antitrust Third Edition, Cambridge, MA: The MIT Press.

Wall, Aaron. (undated) "Search Engine History." http://www.searchenginehistory.com, accessed December 30, 2011.

Werden, Gregory J. 1998, "Demand Elasticities in Anti-trust Analysis." Antitrust Law Journal, 66: 363414.

Womack, Brian. 2011. "Microsoft Nears No. 2 Spot in U.S. Internet Search Market as Yahoo Slips." Bloomberg, http://www.bloomberg.com/news/2011-12-15/microsoft-nears-no-2-spot-in-searchmarket-as-yahoo-slips-1-.html, accessed January 2, 2012. 